\title{
Heme Redox Cycling in Soybean Peroxidase: Hypothetical Model and Supportive Data
}

\author{
Akiha Takayama, Takashi Kadono and Tomonori Kawano* \\ Laboratory of Chemical Biology and Bioengineering, \\ Faculty and Graduate School of Environmental Engineering, \\ The University of Kitakyushu, Kitakyushu, 808-0135, Japan
}

(Received December 1, 2010; accepted Feburary 25, 2011)

Key words: biomaterial, biosensor, plant, protein, enzyme

In plants, the peroxidase family is involved in a great deal of oxidation reactions essential for living cells, using $\mathrm{H}_{2} \mathrm{O}_{2}$ as an electron acceptor and a variety of substrates as electron donors. Nowadays, plant peroxidases are widely used as biological sensing materials in various areas such as medical diagnosis, biosensors, and nanotechnology. Among plant peroxidases, horseradish peroxidase (HRP) and soybean peroxidase (SBP) are widely used as model enzymes applicable to various purposes. For the purpose of providing a basis for future innovation by using SBP as a sensing material, we focus on the behavior of purified SBP in responses to known plant peroxidase substrates reportedly involved in superoxide-generating reactions. A chemiluminescence study showed that SBP can catalyze the generation of superoxide in the presence of salicylic acid and indole-3-acetic acid used as the tester substrates for examining the involvement of the conventional peroxidase cycle (involving native form, Compounds I and II) and oxygenase cycle (involving native form, ferrous form, and Compound III), respectively. Enzyme intermediates in the above two redox cycles were spectroscopically determined by recording the typical spectra reflecting the presence of Compound II (peroxidise cycle) and Compound III (oxygenase cycle). Interestingly, addition of nitric oxide in the absence of $\mathrm{H}_{2} \mathrm{O}_{2}$ resulted in the formation of an intermediate resembling Compound II, the catalytically active form in the peroxidase cycle; thus, the novel gaseous regulation of SBP-mediated reaction was proposed.

\section{Introduction}

A group of pioneering researchers of plant peroxidases in Switzerland metaphorically described that plant peroxidases possess more functions than a 'Swiss army knife.'(1) Nowadays, plant peroxidases are widely used as biological sensing materials in various areas including medical diagnosis,(2) environmental engineering, ${ }^{(3)}$ industry-oriented

*Corresponding author: e-mail: kawanotom@gmail.com 
organic chemistry, ${ }^{(4)}$ biosensors, ${ }^{(5,6)}$ biofuel cells, ${ }^{(7)}$ and nanotechnology. ${ }^{(8,9)}$ In plants, peroxidases are involved in a great deal of oxidation reactions essential for cells, using $\mathrm{H}_{2} \mathrm{O}_{2}$ as an electron $\left(\mathrm{e}^{-}\right)$acceptor and a variety of substrates as $\mathrm{e}^{-}$donors. ${ }^{\left({ }^{10}\right)}$ Living plants can respond to and combat a variety of life-threatening biotic and abiotic stimuli by synthesizing or inducing certain isoforms of peroxidases at a specific time and location, by making use of a variety of plant peroxidase functions. ${ }^{(11,12)}$ Among the various plant peroxidases, the enzymes isolated from horseradish (horseradish peroxidase, HRP) and soybean (soybean peroxidase, SBP) are widely used as model enzymes applicable to various purposes in various areas. Although the use of HRP is highly popular compared with that of SBP, in some occasions, SBP shows better performance than HRP. In clinical diagnosis for thyroid cancer markers with chemiluminescent enzymelinked immunosorbent assay, SBP is 10 -fold more sensitive than HRP. ${ }^{13)}$ For the in vitro synthesis of specific polymers, SBP but not HRP is required.(4) In addition, SBP has recently attracted the attention of plant molecular engineers, since SBP contains $\mathrm{N}$-terminal and C-terminal propeptides that function as signal peptides contributing to the increase in the yield of foreign protein production in genetically engineered plants.(14)

The redox cycles of plant peroxidases are largely analogous to those found in other hemoproteins. Previously, we carried out studies on the oxidation status of various heme proteins including plant peroxidases (such as tobacco peroxidases and HRP). While peroxidases are likely considered as scavengers of reactive oxygen species (ROS), they surely catalyze the generation of ROS such as superoxide anion radicals $\left(\mathrm{O}_{2}{ }^{-}\right)$depending on the combination of substrates (as summarized in our review ${ }^{(15)}$ ). Overall interconversions among the native form, ferrous form, Compounds I, II, and III, and irreversibly inactivated form (known as P-670) of HRP are summarized in the hourglass model (Fig. 1). While the behaviors of tobacco peroxidase and HRP during

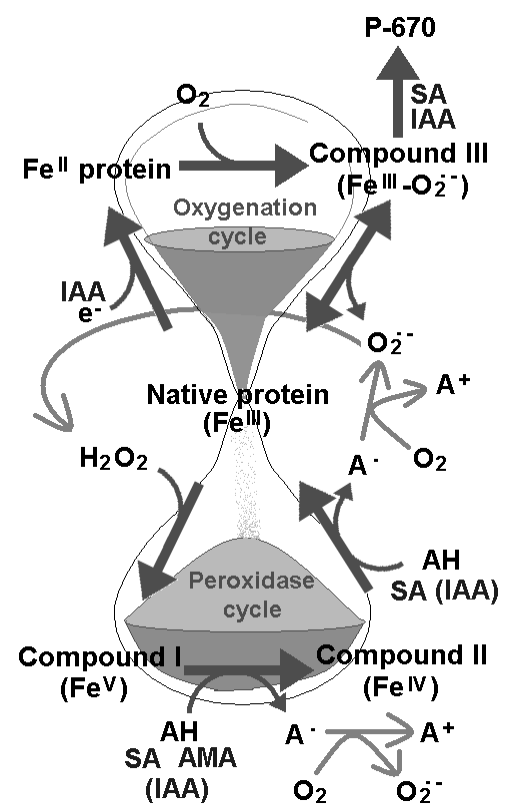

Fig. 1. Hourglass model that summarizes the interconversions among active and inactive forms of peroxidase. The model was modified from Kawano (2003)(15) and Kawano et al. (2005).(24) AMA stands for aromatic monoamines. 
$\mathrm{O}_{2}{ }^{--}$generation reactions in responses to redox active substrates (plant hormones) such as indole-3-acetic acid (IAA) and salicylic acid (SA) have been studied in detail, we still do not know the changes in the oxidation status of SBP induced by these substrates. Owing to the importance of SBP, we need to test if the redox cycling found in other plant peroxidases can be found in SBP or not. In the present study, we focus on the behavior of purified SBP in responses to known natural peroxidase substrates reportedly involved in $\mathrm{O}_{2}{ }^{-}$-generating reactions through spectroscopic and chemiluminescence analyses. This study provides a basis for future innovation by using SBP as a sensing material.

\section{Materials and Methods}

\subsection{Chemicals}

Purified soybean peroxidase (SBP) was purchased from Sigma (St. Louis, MO., USA) and used without further purification. Cypridina lucifenin analog (CLA; 2-methyl6-phenyl-3, 7-dihydroimidazo[1,2-a]pyrazin-3-one) was purchased from Tokyo Kasei Kogyo Co. (Tokyo, Japan). SA, IAA, and other chemicals were purchased from Wako Pure Chemical Co. (Osaka, Japan). IAA solution was prepared by first dissolving $100 \mathrm{mM}$ IAA in ethanol and diluting to the desired concentrations with distilled water heated to $80^{\circ} \mathrm{C}$. Then, the IAA solution was kept on ice in the dark until used. The final concentration of ethanol in the reaction mixture was adjusted to $0.1 \%(\mathrm{v} / \mathrm{v})$.

\subsection{Spectroscopy}

The concentration of SBP was determined spectroscopically by measuring the concentration of heme $\left(\varepsilon 403 \mathrm{~nm}=102 \mathrm{mM}^{-1} \cdot \mathrm{cm}^{-1}\right){ }^{(16)}$ Absorption spectra of SBP in $20 \mathrm{mM}$ potassium phosphate buffer ( $\mathrm{pH}$ 6.0) were recorded using a spectrophotometer (Shimadzu UV-1800, Kyoto, Japan) at room temperature with a spectral bandwidth of $1.0 \mathrm{~nm}$ in a cuvette with a $1 \mathrm{~cm}$ light path. Compounds II and III were prepared by adding $10 \mu \mathrm{M}$ and $1 \mathrm{mM} \mathrm{H}_{2} \mathrm{O}_{2}$ to the native SBP $(7.5 \mu \mathrm{M})$, respectively. Then substrates (SA, IAA) and/or nitric oxide were added to the native enzyme or preformed enzyme intermediates (Compound II or III) and mixed well. Then, induced spectral changes were monitored.

\subsection{Chemiluminescence analysis}

The generation of $\mathrm{O}_{2}{ }^{-}$in the SBP reaction mixture was monitored on the basis of the $\mathrm{O}_{2}{ }^{-}$-specific chemiluminescence of CLA using a luminometer (Luminescensor PSN AB2200-R, Atto Corp., Tokyo, Japan) and expressed as relative chemiluminescence unit (rcu) as previously described for the HRP-catalyzed generation of $\mathrm{O}_{2}{ }^{-{ }^{-}} \cdot(17)$

\subsection{Treatment with nitric oxide (NO)}

The native SBP solution (in a $15 \mathrm{ml}$ plastic test tube) was exposed to bubbling with a $\mathrm{NO} / \mathrm{N}_{2}$ gas mixture (NO concentration, 792 ppm; flow, $45 \mathrm{ml} / \mathrm{min}$; Japan Fine Products Co. Ltd., Kanagawa, Japan) for 5 min. Then, spectroscopic changes in the SBP solution were monitored. 


\section{Results and Discussion}

\subsection{SA-induced $\mathrm{O}_{2}{ }^{--}$generation catalyzed by SBP}

Oxidations of SA and IAA are typical examples of the key functions of the 'plant army knife' used for the generation of ROS; thus, SA and IAA are two typical substrates for plant peroxidase reactions leading to the generation of $\mathrm{O}_{2}^{-{ }^{-} \cdot(15)}$

As shown in Fig. 2(a), the addition of SA to the SBP solution resulted in an immediate burst of $\mathrm{O}_{2}{ }^{--}$production, similarly to previous reports on SA action against tobacco peroxidase ${ }^{(18)}$ and HRP. ${ }^{19)}$ Thus, the catalytic action of SBP for SA-dependent $\mathrm{O}_{2}{ }^{-}$-generation was confirmed for the first time. The following are the proposed reactions for the SA-dependent generation of $\mathrm{O}_{2}{ }^{--}$catalyzed by plant peroxidases:

$$
\begin{aligned}
& \text { Native }^{(\mathrm{III})}+\mathrm{H}_{2} \mathrm{O}_{2} \rightarrow \text { Comp. } \mathrm{I}^{(\mathrm{V})}+\mathrm{H}_{2} \mathrm{O}, \\
& \text { Comp. } \mathrm{I}^{(\mathrm{V})}+\mathrm{SA} \rightarrow \text { Comp. II }{ }^{(\mathrm{IV})}+\mathrm{SA}
\end{aligned}
$$

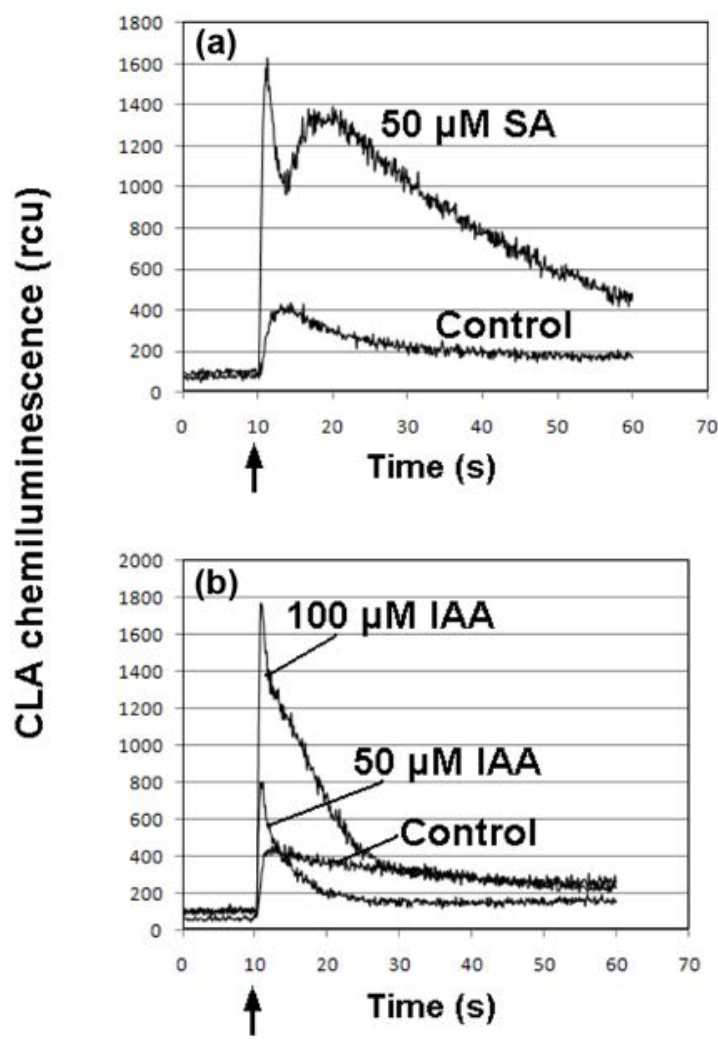

Fig. 2. SBP-catalyzed superoxide generation induced by SA and IAA. Arrows indicate the timing of chemical additions. 


$$
\begin{gathered}
\text { Comp. } \mathrm{II}^{(\mathrm{IV})}+\mathrm{SA} \rightarrow \mathrm{Native}^{(\mathrm{III})}+\mathrm{SA}, \\
2 \mathrm{SA}^{\cdot}+2 \mathrm{O}_{2} \rightarrow 2 \mathrm{SA}++2 \mathrm{O}_{2}^{--},
\end{gathered}
$$

where Native, Comp. I, and Comp. II are native ferric peroxidase and its Compounds I and II, respectively. $\mathrm{SA}^{*}$ and $\mathrm{SA}^{+}$are free radical species and the two-electron oxidized intermediate product, respectively. Roman numerals in the parentheses indicate the formal oxidation states of the heme.

Here, SA behaves as the donor of $\mathrm{e}^{-}$, while $\mathrm{H}_{2} \mathrm{O}_{2}$ acts as the acceptor of $\mathrm{e}^{-}$. Then, the released SA- may react with $\mathrm{O}_{2}$ to form $\mathrm{O}_{2}{ }^{-}$. Because $\mathrm{O}_{2}{ }^{--}$can be readily converted to $\mathrm{H}_{2} \mathrm{O}_{2}$, one cycle of SA-oxidizing peroxidase reaction started with a single unit of $\mathrm{H}_{2} \mathrm{O}_{2}$ results in a yield of two units of $\mathrm{O}_{2}{ }^{-}$equivalent to two units of $\mathrm{H}_{2} \mathrm{O}_{2}$; thus, the total amount of ROS members is amplified. An important consequence of SA' and ROS formation is the induction $P R-1$ gene expression in plants. ${ }^{(20)}$

Experimental evidence in support of the production of SA species $^{(19)}$ has been obtained from an ESR study using ascorbate as a sensitive spin trapper. The likely structures for $\mathrm{SA}^{\cdot}$ and $\mathrm{SA}^{+}$were proposed by an Italian scientist(21) after our earlier studies. Taken together, the above study suggests that SA can be used as a tester substrate for showing the presence of the peroxidase-cycle-dependent $\mathrm{O}_{2}{ }^{-}$-generating pathway (Fig. 1).

\subsection{Metabolism of IAA by plant peroxidases}

Addition of IAA to SBP also resulted in the immediate generation of $\mathrm{O}_{2}{ }^{-}$[Fig. 2(b)], which is the confirmation of IAA action reported for HRP.(16,17) Interaction of IAA and plant peroxidases is not identical to the case of SA oxidation.

Metabolism of IAA, the principal form of auxin in higher plants, is of great interest to plant biologists. Plant peroxidases are considered to be involved in the metabolism of IAA, by oxidizing IAA via two different mechanisms: a conventional $\mathrm{H}_{2} \mathrm{O}_{2}$-dependent pathway and one that requires $\mathrm{O}_{2}$ but not $\mathrm{H}_{2} \mathrm{O}_{2} \cdot{ }^{(16,22)}$ The conventional peroxidase cycle for the oxidation of various substrates coupled to the consumption of $\mathrm{H}_{2} \mathrm{O}_{2}$ proceeds as follows: ${ }^{(15)}$

$$
\begin{gathered}
\text { Native }+\mathrm{H}_{2} \mathrm{O}_{2} \rightarrow \text { Comp. } \mathrm{I}+\mathrm{H}_{2} \mathrm{O}, \\
\text { Comp. } \mathrm{I}+\mathrm{S} \rightarrow \text { Comp. II }+\mathrm{P}, \\
\text { Comp. II }+\mathrm{S}+\mathrm{H}^{+} \rightarrow \text { Native }+\mathrm{H}_{2} \mathrm{O}+\mathrm{P},
\end{gathered}
$$

where $\mathrm{S}$ and $\mathrm{P}$ are the substrate and product of its one-electron oxidation, respectively.

IAA can be oxidized by HRP by this mechanism but there is no strict substrate specificity in this conventional $\mathrm{H}_{2} \mathrm{O}_{2}$-dependent peroxidase cycle.(15) The plant peroxidases including HRP oxidize IAA also via the $\mathrm{H}_{2} \mathrm{O}_{2}$-independent pathway requiring molecular oxygen $\left(\mathrm{O}_{2}\right)$, since most plant peroxidases are considered to be highly specific IAA oxygenases, which possess the domains structurally similar to a specific motif in 
auxin-binding proteins. ${ }^{(16)}$ The proposed reaction cycle for IAA oxidation ${ }^{(22)}$ is initiated via the formation of a ternary complex, enzyme-IAA-dioxygen, yielding IAA cation radicals and $\mathrm{O}_{2}{ }^{-}-$as by-products as follows:

$$
\begin{gathered}
\mathrm{E}+\mathrm{IAA} \leftrightarrow[\text { E-IAA }], \\
{[\text { E-IAA }]+\mathrm{O}_{2} \leftrightarrow\left[\text { E-IAA-O }{ }_{2}\right],} \\
{\left[\text { E-IAA-O }_{2}\right] \rightarrow \text { E }+ \text { IAA }^{\cdot+}+\mathrm{O}_{2}^{-{ }^{-}},}
\end{gathered}
$$

where IAA ${ }^{*+}$ stands for the IAA cation radicals. Thus, plant peroxidases catalyze the IAA-dependent generation of $\mathrm{O}_{2}{ }^{-}$in the absence of $\mathrm{H}_{2} \mathrm{O}_{2}$. However, the nature of the enzyme during the formation of enzyme-substrate complexes such as [E-IAA] and [E-IAA- $\mathrm{O}_{2}$ ] has not been identified. Furthermore, this model does not explain an additional action of IAA as a suicide substrate against HRP by which HRP is irreversibly inactivated. ${ }^{(23)}$ Previously, we suggested that the oxidation statuses of HRP intermediates formed in the presence of IAA, namely, [E-IAA] and [E-IAA- $\mathrm{O}_{2}$ ], may be ferrous enzyme and the $\mathrm{O}_{2}$-bound form of the enzyme (Compound III) in the oxygenease cycle of peroxidases, respectively. ${ }^{(24)}$ Therefore, IAA can be used as a tester substrate for showing the presence of the oxygenase-cycle-dependent $\mathrm{O}_{2}{ }^{--}$-generating pathway (Fig. 1).

\subsection{Spectral examination of the redox intermediates of SBP}

The redox cycles of plant peroxidases are largely analogous to those found in other hemoproteins. The overall interconversions among the native form, ferrous form, Compounds I, II, and III, and irreversibly inactivated form (P-670) of plant peroxidase are summarized in an hourglass model (Fig. 1). Compounds I and II of plant enzymes are considered to possess the hemes at ferryl states with and without additional porphyrin radicals, ${ }^{(25,26)}$ respectively. Thus, Compounds I and II are analogous to the ferryl hemoglobin intermediates from human with and without additional globin radicals, respectively. Interestingly, like plant enzymes (Compound I), the ferryl intermediates of human hemoglobin oxidize aromatic monoamines (AMAs), leading to the production of AMA radicals and $\mathrm{O}_{2}{ }^{--}$,(27) through the catalytic cycle, so-called pseudoperoxidase cycle, which is equivalent to the peroxidase cycle in Fig. 1.

To date, our knowledge on the overall interconversions of the oxidation status among redox intermediates of SBP has been very much limited. Therefore, we obtained spectral data typical to different oxidation statuses of the enzyme, namely, native form (absorption maxima; 403, 500, $639 \mathrm{~nm}$ ), catalytically active form known as Compound II (absorption maxima; 420, 527, $556 \mathrm{~nm}$ ), temporally inactive form known as Compound III (absorption maxima; 415, 545, $578 \mathrm{~nm}$ ), and irreversibly inactivated form, so-called verdohemoprotein or P-670 (absorption maximum, $670 \mathrm{~nm}$ ) in SBP solution kept at ambient temperature $\left(23 \pm 0.5^{\circ} \mathrm{C}\right)$ (Fig. 3). However, the spectral monitoring of two unstable intermediates of SBP, Compound I (readily converted to Compound II) and ferrous enzyme (rapidly converted to Compound III in the presence of dissolved oxygen) was excluded owing to the limit of our experimental design.

Compounds II and III were shown to be formed upon the addition of low [Figs. 3(d) 

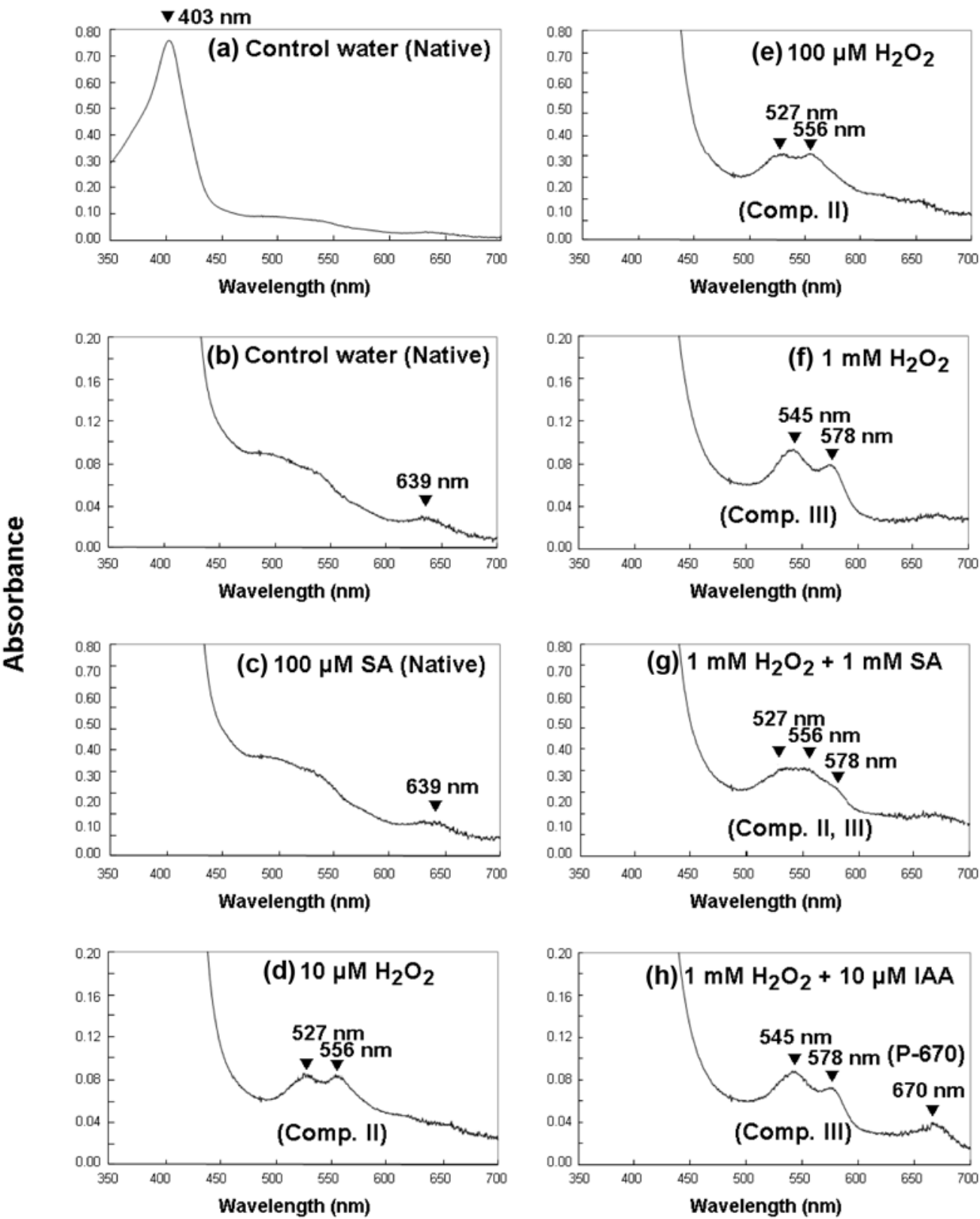

Fig. 3. Spectroscopic observation of Compound II, Compound III, and P-670 of SBG. To native enzyme (a, b), $100 \mu \mathrm{M}$ SA (c), $10 \mu \mathrm{M} \mathrm{H}_{2} \mathrm{O}_{2}$ (d), $100 \mu \mathrm{M} \mathrm{H}_{2} \mathrm{O}_{2}$ (e), $1 \mathrm{mM} \mathrm{H}_{2} \mathrm{O}_{2}$ (f), $1 \mathrm{mM} \mathrm{H}_{2} \mathrm{O}_{2}+1$ mM SA (g), and $1 \mathrm{mM} \mathrm{H}_{2} \mathrm{O}_{2}+10 \mu \mathrm{M}$ IAA (h) were added. Typical spectra for native form (a, b, c), Compound II (d, e), Compound III (f), and P-670 (h) were obtained. 
and 3(e)] and high [Fig. 3(f)] concentrations of $\mathrm{H}_{2} \mathrm{O}_{2}$, respectively. The behaviors of SBP Compound III in response to two known suicide substrates for HRP compound III (enhancing the formation of P-670), namely, SA ${ }^{(28)}$ and IAA,(23) were examined. Formation of the irreversibly inactivated verdohemoprotein was observed only after IAA addition [Fig. 3(h)] but not after SA addition [Fig. 3(g)]. In this point, the feature of SBP differs from that of HRP.

\subsection{Effect of nitric oxide (NO)}

The oxygen-bound form of heme proteins (known as Compound III), including those from plant peroxidases, is suggested to be the source of $\mathrm{O}_{2}{ }^{--}$production in plants under environmental stresses or attacks by pathogens. ${ }^{(29)}$ One mechanism for the conversion of native peroxidase to Compound III involves a drastic $\mathrm{pH}$ change (alkalinization at apoplast) induced by pathogen attacks. However, the mechanism of Compound III formation has not yet been clarified. We previously predicted that the oxygen-bound form of heme proteins known as Compound III can be formed from the native enzyme of plant peroxidase upon interaction with NO, which can be formed during plant-microbe interactions.

The above hypothesis was tested here by exposing the SBP solution to NO-rich gas (Fig. 4). Despite our working hypothesis, exposure to NO resulted in the formation of
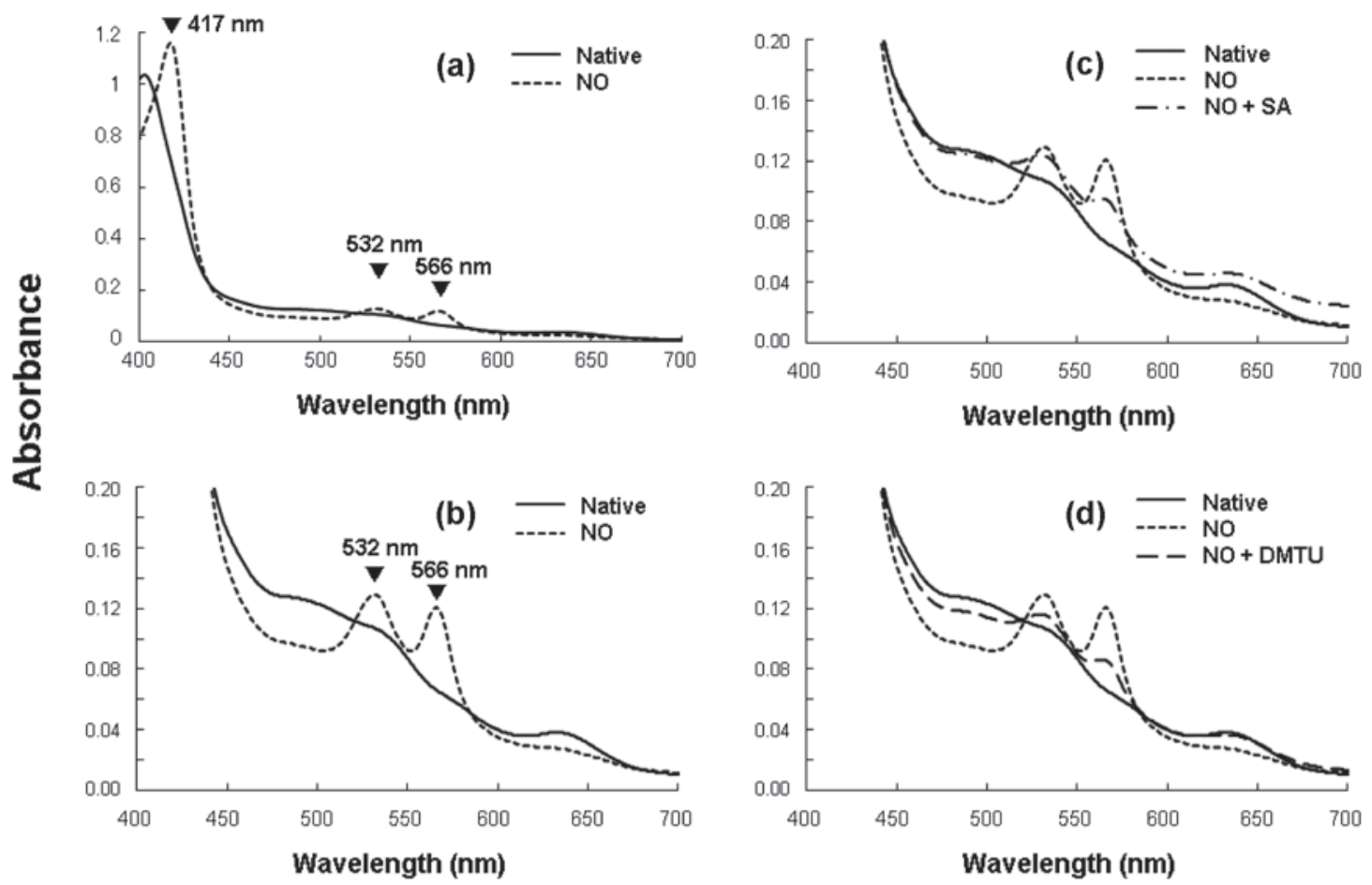

Fig. 4. Spectroscopic evidence in support of NO-dependently formed SBP intermediate. 
an unknown intermediate that possesses absorption maxima at 417, 532, and $566 \mathrm{~nm}$, which resembles Compound II [Figs. 4(a) and 4(b)]. Following the addition of SA, a known tester substrate for peroxidase cycle, which can convert Compound II to the native enzyme, to a NO-dependently formed enzyme intermediate, a large portion of the Compound II-like signal was converted to the native enzyme-like signal [Fig. 4(c)]; thus, this enzyme intermediate is functionally analogous to the natural compound II. Formation of this intermediate was shown to be inhibited in the presence of a radical scavenger, dimethylthiourea (DMTU), suggesting that the native enzyme was converted to this Compound II-like intermediate through the involvement of oxygen radicals possibly induced by NO [Fig. 4(d)].

\subsection{Proposed model catalytic cycles for SBP}

Naturally, plant cells possess several different types of molecular apparatuses for generation of ROS including $\mathrm{O}_{2}{ }^{-}$, such as plasma-membrane-localized respiratory burst oxidase homologs (rboh; plant NADPH oxidases) ${ }^{(30)}$ and redox-active ozoneinduced peptides. ${ }^{(31)}$ Cell-wall-localized peroxidases are one of such molecules capable of $\mathrm{O}_{2}^{-{ }^{-}}$production. (15) $^{-}$In the present study, we focused on the behavior of purified SBP in responses to known tester substrates for plant peroxidases reportedly involved in

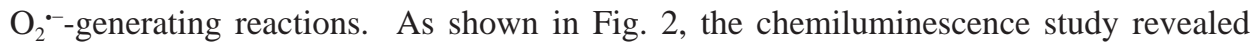
that SBP can catalyze the generation of $\mathrm{O}_{2}^{-}$in the presence of SA and IAA used as the tester substrates for examining the involvement of the conventional peroxidase cycle (involving native form, Compound I, and Compound II) and oxygenase cycle (involving native form, ferrous form, and Compound III), respectively. The enzyme intermediates in the above two redox cycles were spectroscopically determined by recording the typical spectra reflecting the presence of Compound II (peroxidase cycle) and Compound III (oxygenase cycle) (Fig. 3).

The missing pieces within the oxygenation cycle of plant peroxidase are the reducing agents that convert native ferric enzyme (-Fe $\left.{ }^{\mathrm{III}}\right)$ to ferrous enzyme $\left(-\mathrm{Fe}^{\mathrm{II}}\right)$. It is likely that the pH-dependent Compound III-mediated ROS production catalyzed by plant peroxidase ${ }^{(29)}$ requires the formation of Compound III from ferrous enzyme after oxygenation ( $-\mathrm{Fe}^{\mathrm{II}}+\mathrm{O}_{2} \rightarrow-\mathrm{Fe}^{\mathrm{II}}-\mathrm{O}_{2}$ ), since the alternative path of Compound III formation directly from the native enzyme requires $\mathrm{O}_{2}{ }^{--}$or $\mathrm{H}_{2} \mathrm{O}_{2}$, ${ }^{(23)}$ and thus, the sum of ROS consumption $\left(-\mathrm{Fe}^{\mathrm{III}}+\mathrm{O}_{2}{ }^{-} \rightarrow-\mathrm{Fe}^{\mathrm{II}}-\mathrm{O}_{2}\right)$ and production $\left(-\mathrm{Fe}^{\mathrm{II}}-\mathrm{O}_{2} \rightarrow-\mathrm{Fe}^{\mathrm{III}}+\mathrm{O}_{2}{ }^{-}\right.$) becomes zero. Therefore, the formation of ferrous enzyme from native enzyme is important for supporting the oxidative burst via Compound III. This topic has been fully discussed in our previous review articles, by naming possible reducing agents likely present in the plants developing the defense responses. ${ }^{(15,24)}$ Such key putative agents include IAA and also NO as discussed above.

Unexpectedly, the addition of $\mathrm{NO}$ in the absence of $\mathrm{H}_{2} \mathrm{O}_{2}$ resulted in the formation of an intermediate resembling Compound II, the catalytically active form in the peroxidase cycle, thus, suggesting that the peroxidase cycle of SBP can be modified or mimicked by bypassing the native enzyme and Compound II without the involvement of the $\mathrm{H}_{2} \mathrm{O}_{2}$ dependently formed Compound I. Therefore, we can propose a novel gaseous regulation of SBP-mediated reactions with no requirement for $\mathrm{H}_{2} \mathrm{O}_{2}$, although some further 
engineering works are required before actually applying the NO-supplying system for the catalytic process.

Today, intensive studies focusing on the behavior of NO, targeting a variety of heme proteins, are still ongoing in our group using a variety of heme proteins such as HRP, catalase, hemoglobins, cytochrome $c$-derived microperoxidases, etc. We found that there are three distinct types of heme proteins that differed in their responses to NO treatment, namely, (i) a group of hypersensitive heme proteins that are readily and rapidly degraded by the pulse of NO application, (ii) NO-dependently reduced group with the formation of ferrous intermediate and accumulation of Compound III, thus, capable of $\mathrm{O}_{2}{ }^{--}$generation via oxygenase cycle, and (iii) NO-dependently oxidized group that results in the formation of Compound II (unpublished results). Obviously, SBP belongs to the type (iii) group. To understand these NO-dependent pathways in different heme proteins, we need to collect more experimental data.

In conclusion, the present study provided novel information on the redox behavior of SBP as the basis for designing further applications of this plant enzyme as a sensing material.

\section{References}

1 F. Passardi, C. Cosio, C. Penel and C. Dunand: Plant Cell Rep. 24 (2005) 255.

2 L. Saleh and C. Plieth: Nat. Protoc. 5 (2010) 1627.

3 Q. Husain: Rev. Environ. Sci. Biotechnol. 9 (2010) 117.

4 A. Tewari, A. Kokil, S. Ravichandran, S. Nagarajan, R. Bouldin, L. A. Samuelson, R. Nagarajan and J. Kumar: Macromol. Chem. Phys. 211 (2010) 1610.

5 Z. Zhu, X. Sun, Y. Wang, Y. Zeng, W. Sun and X. Huang: Mater. Chem. Phys. 124 (2010) 488.

6 I. Tiwari, K. P. Singh, M. Singh, B. C. Upadhyay and V. S. Tripathi: Anal. Lett. 43 (2010) 2019.

7 A. Pizzariello, M. Stred'ansky and S. Miertus: Bioelectrochemistry 56 (2002) 99.

8 B. L. Allen, G. P. Kotchey, Y. Chen, N. V. K. Yanamala, J. Klein-Seetharaman, V. E. Kagan and A. Star: J. Am. Chem. Soc. 131 (2009) 17194.

9 H. Qiu, L. Lu, X. Huang, Z. Zhang and Y. Qu: Bioresour. Technol. 101 (2010) 9415.

10 C. Penel: The peroxidase system in higher plants, in Integrated Plant Systems, eds. H. Greppin, C. Penel, W. J. Broughton and R. Strasser (Univ. of Geneva, Geneva, 2000) pp. 359-367.

11 S. Hiraga, K. Sasaki, H. Ito, Y. Ohashi and H. Matsui: Plant Cell Physiol. 42 (2001) 462.

12 C. Penel, T. Gasper and H. Greppin: Plant Peroxidases 1980-1990 (Univ. of Geneva, Geneva, 1992).

13 M. M. Vdovenko, A. V. Zubkov, G. I. Kuznetsova, L. D. Ciana, N. S. Kuzmina and I. Y. Sakharov: J. Immunol. Methods 363 (2010) 127.

14 J. A. Schnell, S. Han, B. L. Miki and D. A. Johnson: Plant Cell Rep. 29 (2010) 987.

15 T. Kawano: Plant Cell Rep. 21 (2003) 829.

16 I. G. Gazaryan, L. M. Lagrimini, G. A. Ashby and N. F. Thorneley: Biochem. J. 313 (1996) 841.

17 T. Kawano, N. Kawano, H. Hosoya and F. Lapeyrie: Biochem. Biophys. Res. Commun. 288 (2001) 546.

18 T. Kawano, N. Sahashi, K. Takahashi, N. Uozumi and S. Muto: Plant Cell Physiol. 39 (1998) 721. 
19 T. Kawano and S. Muto: J. Exp. Bot. 51 (2000) 685.

20 M. D. Anderson, Z. Chen and D. F. Klessig: Phytochemistry 47 (1998) 555.

21 F. Gozzo, J. Agric. Food Chem. 51 (2003) 4487.

22 P. A. Savitsky, I. G. Gazaryan, V. I. Tishkov, L. M. Lagrimini, T. Ruzgas and L. Gorton: Biochem. J. 340 (1999) 579.

23 T. Kawano, N. Kawano and F. Lapeyrie: Biochem. Biophys. Res. Commun. 294 (2002) 553.

24 T. Kawano, T. Furuichi and S. Muto: Plant Biotechnol. 21 (2004) 319.

25 R. Rutter, M. Valentine, M. P. Hendrich, L. P. Hager and P. G. Debrunner: Biochemistry 22 (1983) 4769.

26 C. E. Schulz, R. Rutter, J. T. Sage, P. G. Debrunner and L. P. Hager: Biochemistry 23 (1984) 4743.

27 T. Kawano, R. Pinontoan, H. Hosoya and S. Muto: Biosci. Biotechnol., Biochem. 66 (2002) 1224.

28 T. Kawano, S. Muto, M. Adachi, H. Hosoya and F. Lapeyrie: Biosci. Biotechnol., Biochem. 66 (2002) 646.

29 G. P. Bolwell, L. V. Bindschedler, K. A. Blee, V. S. Butt, D. R. Davies, S. L. Gardner, C. Gerrish and F. Minibayeva: J. Exp. Bot. 53 (2002) 1367.

30 H. Yoshioka, F. Bouteau and T. Kawano: Plant Signal. Behav. 3 (2008) 153.

31 K. Yokawa, T. Kagenishi and T. Kawano: Plant Signal. Behav. 6 (2011) 477. 